\title{
Categorias de inovação para os estudos em Comunicação Categories of innovation for communication studies
}

\section{Regina Rossetti}

Doutora em Filosofia com pós-doutoramento pela Universidade de São Paulo (USP) - São Paulo (SP), Brasil; Professora do Programa de Pós-graduação em Comunicação da Universidade Municipal de São Caetano do Sul (USCS) - São Caetano do Sul (SP), Brasil. E-mail: rrossetti@uscs.edu.br

\section{Resumo}

A inovação como fenômeno social, englobando dimensões tecnológicas e simbólicas, é algo presente na sociedade contemporânea midiatizada. Como objeto de discussão acadêmica, a inovação não apresenta uma definição unívoca, pois muitos são os entendimentos possíveis acerca deste conceito e maior ainda o número de termos correlatos. O objetivo deste artigo foi fornecer um quadro de categorias de inovação que possam ser utilizadas nas pesquisas em Comunicação. A metodologia utilizada foi a pesquisa bibliográfica e os referenciais teóricos são advindos das áreas das Ciências Sociais e Humanas, particularmente da Comunicação e da Filosofia. Espera-se com esta pesquisa mapear alguns modos de se dizer o ser da inovação e ampliar as possibilidades de pesquisa sobre inovação no campo da Comunicação.

Palavras-chave: comunicação; inovação; filosofia da comunicação.

\begin{abstract}
Innovation as a social phenomenon, encompassing technological and symbolic dimensions, is something present in contemporary society mediated. As an object of scholarly discussion, innovation does not provide a single definition because there are many possible understandings about this concept and even greater number of related terms. The aim of this article is to provide a framework for innovation categories that can be used in research in communication. The methodology used is the literature and theoretical frameworks are coming from areas of Social Sciences and Humanities, particularly, Communication and Philosophy. It is hoped that this research map some ways to say this is innovation and expand the possibilities of research on innovation in the field of Communication.
\end{abstract}

Keywords: communication; innovation; philosophy of communication. 


\section{Categorias de inovação para os estudos em Comunicação}

\section{Introdução}

A Lei no 10.973, de 2 de dezembro de 2004, denominada "Lei da Inovação", reflete a necessidade de o país contar com dispositivos legais eficientes que contribuam para o delineamento de um cenário favorável ao desenvolvimento tecnológico e ao incentivo à inovação. A partir da constatação de que a produção de conhecimento e a inovação tecnológica geram desenvolvimento, o desafio é de se estabelecer uma cultura de inovação. Neste contexto, o conhecimento é elemento fundamental e a inovação passa a ser veículo de transformação do conhecimento em melhoria da qualidade de vida da sociedade. Projetos de pesquisa em que a inovação seja um dos focos podem contribuir significativamente para o estabelecimento desta cultura da inovação. O governo lança chamadas de financiamento de pesquisas ligadas a Ciência, Tecnologia e Inovação, e espera que nos currículos Lattes dos pesquisadores se registrem projetos, produtos, processos, técnicas, entre outros, sob a tarja da inovação. Embora a ênfase seja por inovação tecnológica, a própria lei fala em cultura de inovação, em conhecimento e desenvolvimento social, ampliando as possibilidades de pesquisa sobre inovação $e$, principalmente, requerendo que o conceito de inovação seja definido. Assim, surge a necessidade de que a inovação seja cada vez mais discutida nos meios acadêmicos como objeto de investigação científica em qualquer área do conhecimento. No campo da Comunicação, a inovação é mais evidente nas interfaces tecnológicas e nas novas mídias. Todavia, a inovação está presente também no impacto social das novas tecnologias de comunicação e informação, no novo receptor, agora produtor e interativo, nos processos cognitivos, nas linguagens, na estética e até mesmo em novas abordagens metodológicas e teóricas de comunicação. Isso, porque a inovação é um fenômeno social, simbólico e tecnológico, presente em toda sociedade contemporânea midiatizada e pode perpassar todo o campo da Comunicação.

Mas o que é inovação e o que se entende por este conceito? Como muitos outros conceitos, este não apresenta uma definição unívoca, pois muitos são os entendimentos possíveis acerca da inovação e, maior ainda, o número de termos correlatos. É preciso, portanto, classificar essas acepções de inovação e fundamentá-las em autores de referência. Para esta explicitação dos diversos conceitos de inovação, a Filosofia pode contribuir muito, pois como diz Deleuze, "a Filosofia é a arte de formar, de inventar, de fabricar conceitos" (Deleuze \& GuatarRi, 2000, p. 10). Então, se é necessário formar, ou até mesmo inventar, o conceito de inovação em seus vários sentidos, é na Filosofia que esta busca encontra aportes para sua realização. Portanto, este artigo parte de uma pesquisa interdisciplinar referente à convergência entre Filosofia e Comunicação. Segundo Braga,

a Comunicação, como todas as CHS, pode se beneficiar de aportes interdisciplinares, e frequentemente o faz. Não há por que opor resistência a esta tendência (contemporaneamente crescente) de articulações entre disciplinas. Ao mesmo tempo, a percepção da forte presença teórica 'alheia' é base para questionamentos interessantes sobre o estado atual da formação do campo (BRAGA, 2004, p.10).

O objetivo é buscar nos estudos teóricos das áreas de Ciências Sociais e Humanas, em particular da Filosofia, a diversidade de aportes conceituais que contribuam para o estudo das inovações na Comunicação. O papel da Filosofia é de elaboração conceitual e metodológica para o tratamento do problema da definição do conceito de inovação em suas várias acepções.

O objetivo deste artigo foi definir o que é inovação e, para tanto, busca mapear seus vários conceitos, os muitos modos de se dizer o seu ser e alguns termos correlatos. A metodologia utilizada foi a pesquisa bibliográfica de referenciais teóricos advindos das áreas de conhecimento das Ciências Sociais e Humanas, particularmente da Comunicação e da Filosofia, e relacionados aos eixos temáticos: inovação na Filosofia e nas Ciências Sociais, inovação na Comunicação.

Esta pesquisa bibliográfica leva à construção de um quadro de categorias em que os vários sentidos de inovação são classificados. Este quadro é elaborado a partir do conceito fundamental de mudança, pois toda mudança traz o novo. A construção deste quadro de categorias de inovação é feita a partir das categorias aristotélicas de substância, qualidade, quantidade, relação, lugar, tempo, ação e paixão, em que são organizados os seguintes termos relativos ao conceito de inovação: novo, novidade e mudança; criação, invenção, alteração, modificação, transformação, multiplicação, diferenciação, diversificação, salto, transposição, tradução, mudança, evolução, ruptura; mutação, variação, incremento, adaptação, apropriação, experimentação; renovação, recriação, transubstanciação, transmutação, deformação, reformulação, transfiguração, metamorfose, transmudação, transverter; legítimo, genuíno, singular, diferenciado, diferente, diverso, novidade, incomum, primeiro, primordial, matricial, inédito, original; sujeito inovador e objeto inovado.

Para a construção desse quadro de categorização dos vários tipos de inovação, esta pesquisa bibliográfica 
trata de alguns dos procedimentos inovativos que foram objeto de estudo da Filosofia e das Ciências Sociais, como: criação (BERGSON, 2005; WHITEHEAD, 1979), invenção (CerteAu, 2002; KANT, 2006), alteração (ARIStóteles, 2002; Hegel, 2005), alteridade (Plotino, 2008), modificação (DescarTES, 2007), transformação (KoHLER, 1980; FoucAult, 2007), multiplicação (BenJamin, 2012), diferenciação (Deleuze, 2006; Spencer, 2009), diversificação (Aristóteles, 2002), salto (KieRKEGAARd, 1988; Hegel, 2011), transposição (BENJAmIN, 2011), tradução (QUINE, 2010; Benjamin, 2011), mudança, evolução (BERGson, 2005), ruptura (BACHELARD, 2006; KUHN, 2010). E sobre termos associados à inovação entendida como um substantivo, um produto ou um constructo, a pesquisa versa sobre: legítimo (ChAKRABORTY, 1997), genuíno (AsCENSÃo, 2009), singular (ABREU, 1968), diferenciado, diferente, diverso (Bowie, 2005; Castro, 2008; Cappo, 2003), novidade, incomum (MARANHÃO, 1988), nOVO (HARGIE \& TOURISH, 1996; Alencar, 1995), primeiro (Hargie \& Tourish, 1996), primordial, matricial (ABREU, 1968), inédito (CASTRO, 2008), original (MARANHÃO, 1988; HARGIE \& TOURISH, 1996; Martineli, 2006; Read, 1981).

A partir deste aporte filosófico, o quadro de categorias de inovação é fundamentado e seus conceitos definidos. Não se pretende fazer aqui uma pesquisa positivista com uma classificação rígida dos termos, mas se leva em consideração a presença da hermenêutica e a reflexão no processo de análise e classificação. Isso permitirá relativizar o quadro, pois um mesmo termo pode pertencer a categorias diferentes dependendo da abordagem.

\section{Características e âmbitos do conceito de inovação}

Preliminarmente, inovação é o efeito ou o ato de inovar. Assim, ela pode ser pensada como substantivo (o novo) ou como verbo (inovar).

Primeiro, pensada como efeito, a inovação indica o próprio produto novo e diz respeito tanto à coisa nova que surge do ato de inovar como ao sujeito que se inova: é a inovação entendida como substantivo e precedida de um artigo (a inovação). Trata-se do novo, isto é, de algo que não existe e passa a existir. Trata-se também da novidade, que pode ser a qualidade do novo ou pode ser propriamente aquilo que é novo, isto é, a coisa nova. Em certos casos, pode-se admitir que a novidade de que se trata é a novidade de coisas, substâncias ou entidades. Em outros casos, trata-se da novidade de qualidades e propriedades. A inovação entendida como efeito é dita como substantivo e diz respeito à coisa nova, ao produto novo. Neste sentido, tem os seguintes termos associados: legítimo, genuíno, singular, diferenciado, diferente, diverso, novidade, incomum, novo, primeiro, primordial, matricial, inédito, original (GIACOMINI, 2011) 1 .

Essa inovação pensada como efeito pode estar presente no objeto ou no sujeito.

Quando a inovação está no objeto, o novo pode se referir à totalidade do objeto ou apenas a uma parte do objeto. Quando a inovação é total (diz respeito à totalidade do objeto) tem-se o absolutamente novo, a novidade, aquilo que é inédito e original. A inovação parcial ocorre apenas em parte do objeto e, então, falamos em renovação, incremento, modificação, aperfeiçoamento, em que apenas um detalhe é novo. A inovação total é mais rara e se aproxima das ideias de criação e invenção. Já a inovação parcial é a mais recorrente. No campo da Comunicação, o objeto novo ou inovado pode ser um produto comunicacional, uma teoria da comunicação ou uma linguagem.

Quando a inovação está no sujeito, novo pode ser o enfoque teórico ou a apropriação social. Trata-se da dimensão social e da dimensão epistemológica da inovação. Epistemologicamente, novo pode ser aquilo que é conhecido pela primeira vez e, nesse sentido, pode sugerir o que é estranho e desconhecido. Socialmente, a inovação pode advir da apropriação coletiva que o grupo faz de um produto ou processo. Em outro sentido, tanto o novo conhecimento como a nova apropriação modificam o sujeito e transformam sua visão e sua ação no mundo. No campo da Comunicação, o sujeito novo ou inovador diz respeito aos agentes envolvidos no processo de comunicação (como o emissor e o receptor) e diz respeito também às novas visões teóricas da Comunicação.

Segundo, pensada como ato, na inovação se privilegia o processo ou a ação que gera o novo e diz respeito à ação de inovar, a ação de tornar novo ou renovar: é a inovação entendida como verbo (inovação). Trata-se de inovar, isto é, tornar novo, fazer surgir a novidade. A inovação entendida como verbo é aquela que está em ato, trata-se da ação de inovar, do processo inovador, de procedimentos que fazem surgir a novidade e de movimentos que geram o novo. Alguns desses procedimentos foram objeto de estudo da Filosofia e das Ciências Sociais: criação, invenção, alteração, modificação, transformação, multiplicação, diferenciação, diversificação,

\footnotetext{
1 Estes termos associados foram levantados por Gino Giacomini Filho em pesquisa financiada pela FAPESP, intitulada: Comunicação e ética promocional: limiares da imitação e inovação.
} 


\section{Categorias de inovação para os estudos em Comunicação}

salto, transposição, tradução, mudança, evolução, ruptura. Outros termos são sinonímicos ou próximos desses primeiros: mutação, variação, incremento, adaptação, apropriação, experimentação. Além de alguns termos derivados pelo acréscimo de prefixos: renovação, recriação, transubstanciação, transmutação, deformação, reformulação, transfiguração, metamorfose, transmudação, transverter. No campo da Comunicação, o ato inovador refere-se a ações presentes nos processos comunicativos que geram produtos comunicacionais novos ou inovados.

Observa-se que a inovação é um fenômeno temporal. A inovação como ato e o consequente surgimento do novo implicam na passagem do tempo. Inovação como ato, como processo ou como ação implica movimento, passagem de um estado a outro que dura no tempo. Como fenômeno temporal, a inovação pode ser recente ou histórica. Em sua dimensão temporal, novo pode ser o que tem pouco tempo de existência e pode ser também sinônimo de moderno, recente ou original. Mas pode também dizer a respeito de uma inovação passada.

\section{Categorias de inovação}

Na Lei de Inovação encontra-se a seguinte definição: "Inovação: introdução de novidade ou aperfeiçoamento produtivo ou social que resulte em novos produtos, processos ou serviços". A rigor, o termo novidade somente foi introduzido no pensamento filosófico contemporaneamente, pelo filósofo francês Henri Bergson e pelo inglês Whitehead ${ }^{2}$. Mas o problema do surgimento do novo é objeto do pensamento humano desde a antiguidade. Embora não tenha usado explicitamente o termo novidade, Aristóteles formula os conceitos de ato e potência para enfrentar o problema suscitado pelo conceito de novidade. Fala em ato e potência para dar conta da questão da existência de algo novo junto com a necessidade de explicitar por que e como surge e em que consiste o novo.

Categorias são instrumentos conceituais de investigação das coisas e de expressão linguística. Aristóteles privilegia o ponto de vista linguístico: as categorias são os modos em que o ser se predica das coisas nas proposições, portanto, categorias são os predicados fundamentais das coisas. Entretanto, para além da interpretação semântica, em que categorias são tipos de enunciados que indicam os diversos

2 Segundo Mora (2001, verbete: novidade) "A rigor, este termo foi introduzido como termo técnico na Filosofia apenas por autores que tenham elaborado a doutrina da chamada 'evolução emergente', autores como Bergson e Whitehead"' modos de se dizer, as categorias de Aristóteles podem ser interpretadas em uma concepção ontológica e, nesse sentido, designam as formas como o ser aparece, são modos de ser. Portanto, concebe-se categoria como determinação pertencente ao próprio ser e do qual o pensamento deve servir-se para conhecê-lo e expressá-lo em palavras.

Para Aristóteles, o ser tem muitos significados e um desses grupos de significados é dado pelo ser como ato e como potência (ARISTÓTELES, 2002). Outro grupo é dado pelas categorias: substância, quantidade, qualidade, relação, lugar, tempo, posição, posse, ação e paixão. Movimento é o termo filosófico que significa mudança. O movimento ou a mudança, em geral, é a passagem do ser em potência para o ser em ato.

O ser ou é só em ato, ou é em potência, ou é, ao mesmo tempo, em ato e em potência: e isso se verifica seja na substância, seja nas categorias restantes. Não existe nenhum movimento que esteja fora das coisas: de fato, a mudança sempre ocorre segundo as categorias do ser, e não há nada que seja comum a todas e que não se inclua numa das categorias. Cada uma das categorias, em todas as coisas, existe de dois modos diversos [...] de modo que devem existir tantas formas de movimento e mudança quantas são as categorias do ser (ARISTóteles, 2002, p. 519).

Potência e ato dizem respeito às várias categorias. Consequentemente, o movimento, que é a passagem da potência ao ato, refere-se às várias categorias. Assim, na tábua de categorias de Aristóteles é possível classificar as várias formas de mudança, em especial, nas categorias de substância, qualidade, quantidade e lugar, conforme se pode observar na Tabela 1. Na categoria substância, a mudança é geração e corrupção, segundo a qualidade é

Tabela 1: Categorias de mudança.

\begin{tabular}{l|c}
\hline Categorias aristotélicas & Mudança \\
\hline Substância & Geração e Corrupção \\
\hline Qualidade & Alteração \\
\hline Quantidade & \\
\hline Relação & Translação \\
\hline Lugar & \\
\hline Tempo & \\
\hline Posição & \\
\hline Posse & \\
\hline Ação & \\
\hline Paixão & \\
\hline
\end{tabular}


alteração, segundo a quantidade é aumento e diminuição, e segundo o lugar é translação.

Mudança é o conceito fundamental para a compreensão da inovação, pois toda mudança traz a novidade. Assim, se o objetivo é construir um quadro de categorias de inovação, é a partir do conceito de mudança que isso deve ser feito. Aristóteles formulou a primeira classificação do conceito de mudança, que serve de base neste estudo para a classificação do conceito de inovação.

O sujeito novo ou inovador, o objeto novo ou inovado e os atos que geram inovação (criação, invenção, alteração, modificação, transformação, multiplicação, diferenciação, diversificação, salto, transposição, tradução, evolução, ruptura) podem ser classificados a partir das categorias de Aristóteles. O objetivo dessa classificação é compreender o que é inovação segundo as diferentes figuras de categorias que, por serem distintas, não oferecem significados idênticos ou unívocos do que é inovação. Assim, o que é inovação, segundo as figuras de categorias, designa tantos significados diferentes de ser quantas são as categorias (REALE, 1994, p. 347) e contribuem para uma compreensão mais ampla do que é inovação.

Trata-se dos diversos modos de se dizer o ser da inovação como substância, qualidade, quantidade, relação, lugar, tempo, ação e paixão ${ }^{3}$. Nesse sentido, é possível pensar em uma inovação substancial, uma inovação qualitativa, uma inovação quantitativa, uma inovação relativa, uma inovação espacial, uma inovação temporal, uma inovação ativa e uma inovação passiva. Portanto, a partir de uma análise reflexiva é possível classificar os diversos processos de inovação em oito ${ }^{4}$ categorias aristotélicas, como se pode ver na Tabela 2.

O primeiro modo de ser da inovação (substância) diz respeito à inovação em si. Os cinco seguintes modos de ser da inovação (quantidade, qualidade, relação, lugar, tempo) referem-se aos atos que geram o novo. Os dois últimos modos de ser da inovação (ação e paixão) referem-se ao sujeito e ao objeto marcados pela inovação,

3 Paixão em grego é patos, que significa sofrer a ação de algo ou alguém no sentido de ser passivo na ação.

$4 \mathrm{Na}$ Metafísica, Aristóteles elenca dez categorias, entretanto, estudiosos (REALE, 1994, p.435) consideram que o número mais exato é oito, pois algumas (posição e posse) estão subsumidas sob outras categorias. seja de forma ativa ou passiva. Mudança é o conceito fundamental para a inovação, porque toda mudança gera o novo, entretanto, por ser um conceito genérico que perpassa várias categorias, ele não pode ser classificado como uma das categorias de inovação.

\subsection{Inovação substancial: criação e invenção}

Criação e invenção são conceitos intrínsecos ao conceito de inovação, pois indicam a própria natureza do que é inovação.

Para Aristóteles, a mudança sob a categoria da substância é geração e corrupção. A geração é uma ação decorrente da criação e da invenção, pois estes dois procedimentos fazem surgir o novo. Todavia, a corrupção também pode gerar o novo, no sentido de que algo deteriorado, destruído, adulterado, pode ser considerado novo em relação ao seu estado anteriormente pleno. Neste sentido, os fenômenos tidos como regressivos que levam à dissolução, isto é, a um processo de unificação que tende à supressão das diferenças e à homogeneização, podem ser pensados como inovadores. Trata-se da mudança no sentido da corrupção e da diminuição, que leva a uma inovação que implica retrocesso, empobrecimento.

A criação pode ser relativa ou absoluta. A criação do novo a partir de algo já existente é relativa e própria do ser humano (BERGson, 2005). A criação absoluta é ex nihilo, isto é, a criação a partir do nada, própria das divindades. Já a criatividade é o princípio da novidade (WHITEHEAD, 1979) em que uma ocasião atual, real e efetiva, é uma entidade nova, distinta de qualquer outra entidade. A criatividade humana faz surgir o novo, distinto da simples somatória das partes a partir das quais surgiu. Assim, criação é mais do que o simples rearranjo de elementos preexistentes. Ela faz surgir algo novo que não existia antes, mesmo que de forma relativa. São termos próximos de criação: renovação, recriação, cocriação, transubstanciação e experimentação.

A invenção faz surgir o novo, isto é, algo que não existe passa a existir a partir de sua invenção. Neste sentido, inventar é diferente de descobrir. Na descoberta, a coisa já existia antes, mas ainda não era conhecida porque estava encoberta; já a coisa inventada, não existia antes de sua invenção (KANT, 2006), então, invenção implica surgimento de um produto da Comunicação ou de um processo comunicativo novo e inédito. Em outro sentido, invenção se aproxima de criatividade cotidiana, antidisciplina e apropriação de novos usos (CERTEAU, 2002). 


\section{Categorias de inovação para os estudos em Comunicação}

Tabela 2: Categorias de inovação.

\begin{tabular}{|c|c|c|c|c|}
\hline Categorias aristotélicas & Atos de inovação & Efeitos da inovação & Termos semelhantes & Categorias de inovação \\
\hline Substância & $\begin{array}{l}\text { Criação } \\
\text { Invenção }\end{array}$ & $\begin{array}{l}\text { Inédito } \\
\text { Original } \\
\text { Novo }\end{array}$ & $\begin{array}{c}\text { Renovação } \\
\text { Recriação } \\
\text { Cocriação } \\
\text { Transubstanciação } \\
\text { Experimentação } \\
\text { Legítimo } \\
\text { Genuíno } \\
\text { Singular }\end{array}$ & Inovação substancial \\
\hline Qualidade & $\begin{array}{c}\text { Alteração } \\
\text { Transformação } \\
\text { Modificação }\end{array}$ & Novidade & $\begin{array}{l}\text { Movimento } \\
\text { Mutação } \\
\text { Transmutação } \\
\text { Transmudação } \\
\text { Reformulação } \\
\text { Deformação } \\
\text { Metamorfose } \\
\text { Transfiguração }\end{array}$ & Inovação qualitativa \\
\hline Quantidade & Multiplicação & Múltiplos & Variação & Inovação quantitativa \\
\hline Relação & $\begin{array}{l}\text { Diversificação } \\
\text { Diferenciação }\end{array}$ & $\begin{array}{l}\text { Diverso Diferenciado } \\
\text { Diferente }\end{array}$ & $\begin{array}{l}\text { Dessemelhança } \\
\text { Incomum } \\
\text { Alteridade }\end{array}$ & Inovação relativa \\
\hline Lugar & $\begin{array}{c}\text { Salto } \\
\text { Tradução } \\
\text { Transposição }\end{array}$ & & $\begin{array}{c}\text { Transverter } \\
\text { Adaptação } \\
\text { Transportação }\end{array}$ & Inovação espacial \\
\hline Tempo & $\begin{array}{l}\text { Evolução } \\
\text { Ruptura }\end{array}$ & $\begin{array}{l}\text { Primeiro } \\
\text { Primordial } \\
\text { Matricial }\end{array}$ & $\begin{array}{l}\text { Desenvolvimento } \\
\text { Aprimoramento } \\
\text { Aperfeiçoamento } \\
\text { Progresso } \\
\text { Incremento } \\
\text { Corte }\end{array}$ & Inovação temporal \\
\hline Ação & Sujeito inovador & & & Inovação ativa \\
\hline Paixão & & Objeto inovado & & Inovação passiva \\
\hline
\end{tabular}

O processo de inovação sob a categoria substancial gera aquilo que se chama de inédito, o original, o novo. Nesse aspecto, tem como termos associados: o legítimo, o genuíno, o singular.

\subsection{Inovação qualitativa: alteração, transformação e modificação}

Sob a categoria da qualidade encontram-se a alteração, a transformação e a modificação. Atos intimamente ligados ao conceito de mudança, e toda mudança é capaz de inovar no sentido de fazer surgir novos estados que não se manifestavam anteriormente.
Alteração é a mudança sob a categoria da qualidade, trata-se da aquisição ou da perda de qualidades acidentais (ARISTótelEs, 2002) que alteram um produto comunicacional ou um processo comunicativo. Pode ser entendido como alteração essencial, em que a coisa se torna algo diferente excluindo toda a forma anterior, neste sentido tem-se a alteridade (PLOTINO, 2008). Do ponto de vista dialético, a alteração pode ser a ação ou efeito de alterar-se, pelo qual um ser em si se transforma em seu ser em outro. Mesmo sendo uma mudança radical do ser, o resultado da alteração não anula completamente o que havia antes de alterar-se (HEGEL, 2005). Toda alteração faz surgir novas qualidades 
no produto comunicacional ou no processo comunicativo. Termos correlatos: movimento, mutação e transmutação.

A modificação é a mudança dos modos, apenas é nova a maneira como são o produto da comunicação ou o processo comunicativo, o essencial permanece o mesmo. Modos são as qualidades secundárias mutáveis das substâncias contrapostas aos atributos que constituem as qualidades permanentes ou necessárias (DESCARTES, 2007). Trata-se de uma inovação acessória e não radical. Termo próximo é transmudação.

A transformação é a mudança da forma tanto do produto comunicacional como do processo comunicativo. A noção de transformação é usada em várias esferas: metalinguagem, gramatical, matemática, topológica, psicológica e sociológica. Mas é no Gestaltismo - psicologia da estrutura ou da forma -, e suas transformações de configurações perceptivas a atos de percepção que o termo transformação recebeu mais atenção (KOHLER, 1980). Outro uso frequente diz respeito às transformações de estruturas sociais que permitem explicar a natureza, o desenvolvimento e a mudança dessas estruturas no tempo (FouCAULT, 2007). O caráter de transformabilidade não pode ser eliminado das estruturas. Os estudos estruturalistas investigam as transformações que tornam possível passar de uma estrutura a outra mediante mudanças apenas em seus elementos, sem que haja alteração no sistema estrutural como um todo. Por vezes, as estruturas mudam completamente e a mudança não é entendida como alterações dentro de uma continuidade histórica, mas como cortes que fazem surgir novas estruturas sociais. A transformação traz uma inovação na forma ou na estrutura do produto da comunicação ou do processo comunicativo. São termos correlatos: reformulação, deformação, metamorfose e transfiguração.

A inovação qualitativa produz a novidade, isto é, a qualidade do que é novo.

\subsection{Inovação quantitativa: multiplicação}

A inovação pode estar na multiplicação quantitativa do produto comunicacional. Muitos do mesmo podem ser considerados novos em relação ao único que é original. Algo único tem uma aura original que ao se perder no processo de multiplicação propicia a este algo um novo significado. Trata-se da reprodução que indica mais repetição do que inovação, entretanto, pode mudar o sentido do original (BENJAMIN, 2012). Tanto a multiplicação quanto a reprodução dizem respeito ao tipo de inovação que a massificação traz. A inovação quantitativa é mais tênue e menos percebida do que a inovação qualitativa. Termo próximo: variação.

\subsection{Inovação relativa: diversificação e diferenciação}

A inovação pode estar no produto da comunicação ou processo comunicativo com respeito a outro produto da Comunicação ou processo comunicativo. Diferenciação indica que a inovação se dá a respeito de outra coisa diferente e à alteridade em relação ao outro.

Diversificação é um termo mais genérico do que alteridade, diferença e dessemelhança e pode indicar qualquer um dos três juntos. Alteridade é um conceito mais restrito do que diversidade e mais extenso do que diferença. A diversidade pode ser puramente numérica, a alteridade não. A diferença não é incompatível com a alteridade, e vice-versa. Entretanto, pode indicar a simples distinção numérica de duas coisas que não diferem em nada uma da outra, exceto por serem numericamente distintas, nesse sentido estaria mais próximo da categoria de inovação quantitativa (ARISTÓTELES, 2002). O que é diverso o é pelo fato de simplesmente não ser o mesmo que outra coisa, mesmo que somente numericamente. Neste caso, a inovação não é tão significativa, mas mesmo assim existe no sentido de que muitos de um mesmo podem ser considerados como uma novidade se comparados ao único original.

A diferenciação entre duas coisas implica determinar em que elas diferem. A diferença implica sempre na determinação da diversidade, algo que a alteridade não requer, pois alteridade é o ser outro, o colocar-se ou constituir-se como outro, e este outro pode ser igual ou diferente. $O$ diferente se diz relacionalmente, pois tudo o que é diferente, é diferente em relação a algo (ARISTóteles, 2002). Do ponto de vista lógico, a noção de diferença específica é usada na formulação de uma definição clássica, pois ela faz com que de um gênero se distinga a espécie, por exemplo, racional é a diferença específica do homem em relação ao gênero animal. Diferenciação também pode ser a passagem do homogêneo ao heterogêneo (SPENCER, 2009), que constitui a natureza fundamental da evolução, ao distinguir-se do estado homogênio anterior surge uma nova espécie heterogenia. A diferença traz uma inovação relacional, pois o diferente somente é novo em relação àquilo do qual difere, e vice-versa. A diferença ocorre também pelas diferentes atualizações do virtual (DeleuZE, 2006).

Como produto da inovação realtiva tem-se o diverso, o diferenciado e o diferente. Termos próximos a estes: a dessemelhança, a alteridade, o incomum. 


\section{Categorias de inovação para os estudos em Comunicação}

\subsection{Inovação espacial: salto, tradução e transposição}

A inovação pode estar fora do produto comunicacional ou do processo comunicativo como um lugar, uma situação, uma posição. A inovação acontece pela mudança no sentido de deslocamento, transição ou passagem. Pode ser um salto de um lugar a outro, uma transposição a outro lugar diferente da origem ou uma tradução.

Salto é a passagem brusca e sem mediação de um estado para outro. Salto é a transição com ruptura que ocorre em diversos estados da existência individual e nas modificações que ela experimenta (KierKegaARD, 1988). Por outro lado, dialeticamente, salto pode ser uma transição não gradual, mas sem rupturas, em que a mediação concilia os opostos, trata-se da passagem de uma mudança quantitativa para uma mudança qualitativa (HEGEL, 2011). O salto traz inovação porque rompe com o velho estado e instaura um novo.

Como não existem universais linguísticos nem tampouco mecanismos inatos que torne possível a tradutibilidade pura e simples, há uma indeterminação em toda tradução. Esta indeterminação da tradução sugere a possibilidade de uma variedade de interpretações de uma expressão dada, flexibilidades interpretativas próximas da tradição hermenêutica (QUINE, 2010). Por causa dessa indeterminação, a tradução é sempre nova em relação ao original, visto que o tradutor é obrigado a criar novos significados que traduzam o original (BENJAMIN, 2011). A tradução renova a vida do original pela apresentação daquilo que é essencial, mas ainda não revelado no original.

A transposição é a passagem de um gênero a outro, de um sentido a outro. Trata-se de transpor fronteiras, percorrer distâncias que separam o original daquilo que foi transposto (BENJAMIN, 2011). A transposição é um ato que pode gerar inovação, e pode favorecer o surgimento de novas qualidades e propriedades que não existiam no gênero de partida e que são trazidas à luz no gênero de chegada, tal qual um processo tradutório ou de recriação. Tratam de transposições pensadas como arranjos ou adlaptações de gêneros, de mídias e de sentidos. Tais arranjos implicam mudanças nas linguagens e, ao mesmo tempo, promovem inovações de formato, sintaxe ou conteúdo. Termos próximos: transverter, adaptação, transportação.

\subsection{Inovação temporal: evolução e ruptura}

Existem várias espécies de movimento ou mudança: geração, corrupção, aumento, diminuição, alteração e translação (ARIStóteles, 2002). Consequentemente, a mudança pode ocorrer em várias direções, sem necessariamente ser para melhor ou para pior, e neste sentido a mudança pode ser compreendida como um ato neutro.
Quando a mudança é no sentido da geração, do aumento, tem-se a evolução, que implica continuidade e acréscimo (BERGson, 2005), e desenvolvimento progressivo. A inovação pode acontecer como um processo contínuo de evolução ou aperfeiçoamento. Termos correlatos: desenvolvimento, aprimoramento, aperfeiçoamento, incremento e progresso.

A ruptura é a mudança por meio do corte repentino com o estado anterior e o surgimento descontínuo de um novo estado. Pode ser uma ruptura epistemológica, que nega o velho e faz surgir uma nova teoria (BACHELARD, 2006) ou uma revolução científica como mudança descontínua de paradigmas (KUHN, 2010). A inovação pode surgir de forma abrupta e descontínua, como uma ruptura que faz surgir o novo. O termo correlato é corte.

A inovação temporal gera o novo no tempo: o primeiro, o primordial e o matricial.

\subsection{Inovação ativa: sujeito inovador}

Depois de tratar das categorias referentes aos atos que geram inovação, cumpre falar das categorias ação e paixão, que dizem respeito ao sujeito e ao objeto.

A inovação sob a categoria da ação é tida como inovação ativa, cujo agente é o sujeito inovador. É a inovação pensada como ato em que o processo faz surgir o novo e diz respeito à ação de inovar, a ação de tornar novo, renovar. Diz respeito também ao agente inovador, isto é, o sujeito que inova e, neste sentido, a inovação está no sujeito como seu princípio. No campo da Comunicação, este sujeito inovador diz respeito aos agentes envolvidos no processo de comunicação (como o emissor e o receptor) e diz respeito também às novas visões teóricas da comunicação.

\subsection{Inovação passiva: objeto inovado}

Já a inovação sob a categoria da paixão é tida como uma inovação passiva, em que o objeto inovado sofreu a ação que gerou nele a inovação. É o efeito da inovação que gera um produto inovado. A inovação está no objeto como seu fim. É o novo que surge como resultado do processo de inovação. No campo da Comunicação, este objeto inovado pode ser um produto comunicacional.

\section{Considerações finais}

A partir da necessidade social de estabelecimento de uma cultura da inovação, o fenômeno social, tecnológico e simbólico da inovação se torna objeto de investigação científica, inclusive 
incentivado pela chamada Lei de Inovação. A inovação como objeto de investigação é cada vez mais discutida nos meios científicos e acadêmicos do campo da Comunicação, mas não apresenta uma única definição. Como não há um conceito único de inovação e ela pode ser dita em vários sentidos, este artigo forneceu um quadro de referências no intuito de apresentar, de forma organizada, esses vários sentidos.

Para definição dos diversos conceitos de inovação, pertencentes ao quadro de categorias, foi feito um levantamento

\section{Referências}

Abreu, Edman Ayres. O plágio em música. São Paulo: Editora Revista dos Tribunais, 1968.

Alencar, Eunice M. L. S. Criatividade. Brasília: Editora Universidade de Brasília (UnB), 1995.

Aristóteles. Metafísica. São Paulo: Loyola, 2002.

AsCENSÃo, José de Oliveira. O princípio da prestação: um novo fundamento para a concorrência desleal. Lisboa: APDA - Associação Portuguesa de Direito Autoral. 41p. Disponível em: http://www.apdi.pt.

Bachelard, Gaston. A epistemologia. Lisboa: Edições 70, 2006.

Benjamin, Walter. A obra de arte na época de suas técnicas de reprodução. Porto Alegre: Zouk, 2012.

2011.

A tarefa do tradutor. São Paulo: Editora 34,

Bergson, Henri. A evolução criadora. São Paulo: Martins Fontes, 2005.

Cartas, conferências e outros escritos. São Paulo: Abril Cultural, 1984.

BowIE, James I. Innovation, imitation, legitimacy and deviance in the design of graphicaltrademarks in the United States, 1884-2003. A dissertation submitted to the Faculty of the Department of Sociology. Doctoral of Philosophy. The University of Arizona, 2005.

Braga, José Luiz. Os estudos de interface como espaço de construção do campo da Comunicação. Texto dos vários entendimentos de inovação presentes nos estudos teóricos das áreas de Ciências Sociais e Humanas, em particular, na Filosofia. A contribuição deste artigo para o campo de estudos científicos em Comunicação se encontra na explicitação, fundamentação e classificação dos muitos entendimentos possíveis do conceito de inovação e de seus termos correlatos. Espera-se, com este mapeamento de alguns modos de se dizer o ser da inovação, ampliar as possibilidades de pesquisa sobre inovação no campo de estudos da Comunicação.

proposto ao GT Epistemologia da Comunicação, para a XIII Compós, 2004. Disponível em: http://www.compos. org.br/data/biblioteca_658.pdf

BrasiL. Presidência da República. Lei no 10.973 de 2 de dezembro de 2004. Disponível em: <http://www.planalto. gov.br/ccivil_03/_ato2004-2006/2004/lei/l10.973.htm>. Acesso em: 01 mar 2013

CASTRO, Maria L. Práticas publicitárias: o embaralhamento do discurso promocional. In: Em torno das mídias: práticas e ambiências. DUARTE, Elizabeth; CASTRO, Maria Lília (Orgs.). Porto Alegre: Sulina, 2008, p. 41-53.

Certeau, Michel. A invenção do cotidiano. Petróplis: Vozes, 2002.

Chakraborty, Goutam; Allred, Anthony; Sukhdial, Ajay Singh; BRISTOL,Terry. Use of negative cues to reduce demand for counterfeit products. Advances in Consumer Research. Provo, UT: Association for Consumer Research,. V. 24, p. 345-349, 1997.

Deleuze, Gilles. Diferença e repetição. Rio de Janeiro: Graal, 2006.

Deleuze, Gilles; Guatarri, Felix. O que é a Filosofia? Rio de janeiro: Editora 34, 2000.

Descartes, René. Princípios de Filosofia. São Paulo: Hemus, 2007.

Foucault, Michel. As palavras e as coisas. São Paulo: Martins, 2007.

GıAcominı FILHO, Gino. Comunicação e ética promocional: limiares da imitação e inovação. Relatório de Pesquisa para FAPESP. São Paulo, 2011. 


\section{Categorias de inovação para os estudos em Comunicação}

HARGIE, Colin \& TourISH, Dennis. Corporate communication in the management of innovation and change. Corporate Communications. Bradford. vol. 1, n. 2, 1996, p. 3-12.

Hegel, Georg W. F. Ciência da lógica. São Paulo: Barcarolla, 2011.

Enciclopedia de lãs ciências filosóficas. Madri:

Alianza, 2005.

KAnt, Immanuel. Antropologia de um ponto de vista pragmático. São Paulo: Iluminuras, 2006.

Kierkegatrd, Soren A. Diário. São Paulo: Nova Cultural, 1988.

KoHlen, Wolfgang. Psicologia da Gestalt. São Paulo: Itatiaia, 1980.

Kunn, Thomas. Estrutura das revoluções científicas. São Paulo: Perspectiva, 2010.

LeOPoldo e Silva, Franklin. Bergson: intuição e discurso filosófico. São Paulo: Loyola, 1994.
Maranhão, Jorge. A arte da publicidade: estética, crítica e kitsch. Campinas: Papirus, 1988.

MARTINELI, Fernanda. A Sacralização da marca e a pirataria: comunicação e sociabilidade nas práticas de consumo de bens piratas. Dissertação (Mestrado em Comunicação e Cultura). Universidade Federal do Rio de Janeiro. Rio de Janeiro, 2006.

Plotino. Eneada III: sobre a natureza, a contemplação e o uno. Campinas: Unicamp, 2008.

Quine, Willard. Palavra e objeto. São Paulo: Vozes, 2010.

READ, Herbert. As origens da forma na arte. Rio de Janeiro: Zahar, 1981.

Reale, Giovanni. História da Filosofia antiga. São Paulo: Loyola, 1994.

SPEnCER, Herbert. First principles. Cambridge: Cambridge University Press, 2009.

WHITEHEAD, Alfred North. Process and reality. London: Free Press, 1979. 